\title{
Rheological and thermal properties of EVA-organoclay systems using an environmentally friendly clay modifier
}

\author{
Reinaldo Yoshio Morita', Juliana Regina Kloss², Ronilson Vasconcelos Barbosa ${ }^{3}$, Bluma Guenther Soares ${ }^{4,5}$, \\ Luis Carlos Oliveira da Silva ${ }^{4}$ and Ana Lúcia Nazareth da Silva ${ }^{4,6 *}$ \\ ${ }^{1}$ Coordenação de Engenharia de Bioprocessos e Biotecnologia, Universidade Tecnológica Federal do
Paraná - UTFPR, Dois Vizinhos, PR, Brasil \\ ${ }^{2}$ Departamento de Química e Biologia, Universidade Tecnológica Federal do Paraná - UTFPR, Curitiba, \\ PR, Brasil \\ ${ }^{3}$ Departamento de Química, Universidade Federal do Paraná - UFPR, Curitiba, PR, Brasil \\ ${ }^{4}$ Instituto de Macromoléculas Professora Eloisa Mano - IMA, Universidade Federal do Rio de Janeiro - \\ UFRJ, Rio de Janeiro, RJ, Brasil \\ ${ }^{5}$ Programa de Engenharia Metalúrgica - PEMM, Instituto Alberto Luiz Coimbra de Pós-graduação e Pesquisa \\ de Engenharia - COPPE, Universidade Federal do Rio de Janeiro - UFRJ, Rio de Janeiro, RJ, Brasil \\ ${ }^{6}$ Programa de Engenharia Ambiental, Universidade Federal do Rio de Janeiro - UFRJ, Rio de Janeiro, RJ, Brasil \\ a Selected paper presented at the 15th Brazilian Polymer Conference - (15thCBPol) held in Bento \\ Gonçalves, Brazil, on 27-31 October, 2019.
}

*ananazareth@ima.ufrj.br

\begin{abstract}
EVA systems, using an environmentally friendly organoclay modified with a non-ionic and free of ammonium ions modifier (BN-AM), were prepared in a single-screw laboratory extruder and characterized by rheological, morphological and thermal properties. WAXD analysis suggested that the nanocomposites with $1.5 \mathrm{wt} \%$ of BN-AM presented an exfoliated structure, while the rheological results showed that the nanocomposites with BN-AM organoclay tended to present a more pronounced shear thinning behavior when compared to EVA and the nanocomposites with the traditional organoclay. The SEM/EDS analysis by using elemental mappings showed good dispersion of the organoclays (BN-AM and BN-CT) in the EVA matrix. Thermogravimetry analysis showed an improvement in thermal stability of EVA when the non-ionic modifier was used instead of the traditional one. In general, it was concluded that the addition of low content of BN-AM organoclay in EVA matrices is a promising option for the production of nanocomposites.
\end{abstract}

Keywords: EVA nanocomposite, organoclay, rheological property, thermal property, morphology.

How to cite: Morita, R. Y., Kloss, J. R., Barbosa, R. V., Soares, B. G., Silva, L. C. O., \& Silva, A. L. N. (2020). Rheological and thermal properties of EVA-organoclay systems using an environmentally friendly clay modifier. Polimeros: Ciência e Tecnologia, 30(3), e2020028. https://doi.org/10.1590/0104-1428.03420

\section{Introduction}

Poly(ethylene-co-vinyl acetate) (EVA) clay nanocomposite thermoplastics have several industrial applications, such as greenhouse films ${ }^{[1,2]}$, wires and cables ${ }^{[3,4]}$. The versatility of EVA nanocomposites is due to a synergic effect between the acetate group on the chains and the modified clay. Several studies have demonstrated improvements in mechanical properties $^{[5-7]}$, flame retardant ${ }^{[8-10]}$, and gas barrier for organoclays $^{[11-13]}$.

Organoclay (organically modified clay) has been used since 1990 to prepare polymeric nanocomposites ${ }^{[5,14]}$. Mineral clays, especially montmorillonite (MMT), are natural hydrophilic agents present in bentonite. A main feature of MMT is swelling in water, due to the presence of mono- or divalent cations $\left(\mathrm{Na}^{+}\right.$or $\left.\mathrm{Ca}^{2+}\right)$ in the galleries, usually following an ion-exchange reaction involving an organic modifier such as an alkylammonium or alkyl phosphonium surfactant. These organically modified clays contain organic species in the galleries, which change the basal spacing and the polymer-clay affinity, and they are importance to the morphology and properties of micro and nanocomposites ${ }^{[15-18]}$.

Polymer clay nanocomposites prepared via a melting process are industrially convenient because this process is environmentally friendly and low-cost. However, it is not always possible to obtain a sufficient interaction between the polymer and the organoclay to achieve the desired level of exfoliated structures. Previous studies have indicated that the nature and alkyl-chain length of the modifier affect the structure of nanocomposites ${ }^{[19,20]}$. The rheological behavior of nanocomposites may reveal information about the relationship 
of the polymer chain and organoclays structure. Lee and $\mathrm{Han}^{[21]}$ evaluated the rheological behavior of nanocomposites of systems based on two organoclays treated with a surfactant having polar and non-polar group and different gallery distances, in addition, they have chosen a polymer matrix having a wide range of polarity from partly polar EVA to highly polar poly(ethylene-co-vinyl alcohol) EVOH. The experimental results showed significant differences in the degree of exfoliation of organoclay and rheological responses in terms of the compatibility between polymer matrix and the surfactant residing at the surface of organoclay and the gallery distance of the organoclays. The authors pointed out that polymer melt viscosity plays an important role in dispersing the organoclay.

The mainstream techniques for preparing polymerclay nanocomposites are extrusion and injection molding, which generate a high-shear environment for delaminating or exfoliating the clay platelets in the polymer matrix. The modifier may decompose during the process, at the typical melt-processing temperatures of some matrices. Usually, the onset temperature for MMT modified by alkylammonium ions is around $180{ }^{\circ} \mathrm{C}^{[22]}$.

Therefore, other types of modifiers, such as non-ionic modifiers, are being used ${ }^{[23,24]}$. In a previous study, we examined the mechanical and thermal properties of the EVA nanocomposites containing non-ionic modified clays. The nanocomposites were prepared using two different natural clays and clay modifiers, ammonium ion and a non-ionic modifier. The results clearly showed that the non-ionic modifier behaved similarly to the ammonium-salt modifier. However, the organically modified clays proved to be more compatible with the polymer matrix than did the natural clay ${ }^{[25]}$.

Carli et al. ${ }^{[26]}$ studied nanocomposites reinforced by a nonionic organoclay, which showed improvement in properties. The authors compared the morphology and the thermal and mechanical properties of nanocomposites prepared using commercial organically modified montmorillonite, raw montmorillonite and non-ionic organoclay. They found that the nanocomposite using non-ionic surfactants was more chemically stable than the commercial cationic organoclays.

The novelty of the present work is the addition of a new organoclay synthetized with a non-ionic surfactant, free of ammonium salt, which makes it more environmentally friendly ${ }^{[27-29]}$. BN-AM was added to an EVA matrix and the system characterized by WAXD, rheological and thermal analyzes and the results obtained were compared to similar systems containing a traditional organoclay.

\section{Materials and Methods}

\subsection{Materials}

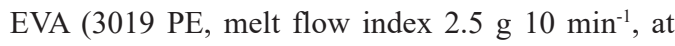
$190^{\circ} \mathrm{C}, 2.16 \mathrm{~kg}, 18 \mathrm{wt} \%$ vinyl acetate content) was supplied by Braskem. The non-ionic organoclay was prepared by modifying the sodium bentonite Vulgel CN 45 with a nonionic surfactant containing 18 carbon atoms and supplied by Ioto International ${ }^{[28,29]}$. The organoclay modified with cetyltrimethylammonium bromide (CTAB) was prepared
Table 1. Identification of the types of modifier and organoclays.

\begin{tabular}{ccc}
\hline Bentonite & Type of Modifier & Designated \\
\hline Vulgel CN 45 & non-ionic & BN-AM \\
& cetyltrimethylammonium bromide & BN-CT \\
\hline
\end{tabular}

by the ion-exchange method, using the same sodium bentonite (Table 1).

Both organoclays and sodium bentonite Vulgel CN 45 had their physical and chemical properties characterized and disclosed in previous work ${ }^{[27]}$. In that work, the authors reported that the BN-AM showed the lower iron content and it was considered, among the other studied organoclays, the more promising one for nanocomposite use in nanocomposite preparation. Thus, in the present study, the BN-AM organoclay was chosen to be added to EVA matrix and the materials produced were compared to EVA/BN-CT compositions.

\subsection{Methods}

\subsubsection{Composite preparation by melt processing}

EVA composites with 1.5 and $3.0 \mathrm{wt} \%$ were prepared with a $\mathrm{MH}$ Equipment $\mathrm{MH} 50 \mathrm{H}$ model intensive homogenizer operating at 3,600 rpm for $10 \mathrm{~s}$. And, melt mixture was processed in a single-screw laboratory extruder, BGM EL-45 model, $\mathrm{L} / \mathrm{D}=40: 1$ and $\mathrm{D}=25 \mathrm{~mm}$. The temperature profile used was $135 / 140 / 150{ }^{\circ} \mathrm{C}$ at $200 \mathrm{rpm}$. After, the extruded was pelletized. The pellets obtained were injection molded using a Romi Primax 65R injector with a temperature profile ranging from 160 to $180{ }^{\circ} \mathrm{C}$ in the 4 zones with a mold for tensile test specimen (ASTM D638 Type 1). The injection pressure was 300 bar and the holding pressure was 150 bar, for $2 \mathrm{~s}$.

\subsubsection{Characterization}

The dynamic melt rheological properties of the neat EVA and the EVA composites were measured in order to gain a fundamental understanding of the processability and the relationship between the structure and the properties of the materials. Melt rheological measurements were performed on a TA Instruments TRIOS Discovery HR-1 rheometer in parallel-plate geometry, using $25 \mathrm{~mm}$-diameter parallel plates. All tests were conducted at $180{ }^{\circ} \mathrm{C}$. The linear viscoelastic zone was assessed by performing strain sweep tests from 0.1 to $100 \%$ at $1 \mathrm{~Hz}$. Frequency sweep tests from 0.01 to $600 \mathrm{rad} \mathrm{s}^{-1}$ were performed at $1 \%$ strain under nitrogen atmosphere. The rheological analysis was conducted from a piece cut out from the tensile test specimen. Wide angle X-ray diffraction analysis (WAXD, Shimadzu XRD-6000) was operated at $40 \mathrm{kV} / 30 \mathrm{~mA}$ with $\mathrm{Cu} \mathrm{K} \alpha$ radiation (wavelength, $\lambda=0.154 \mathrm{~nm}$ ). The samples were scanned with the diffraction angle $2 \theta$, ranging from $2^{\circ}$ to $50^{\circ}$ at a scan rate of $1.0^{\circ} \mathrm{min}^{-1}$ in $2 \theta$. Scanning electron microscopy (SEM) and energy dispersive spectroscopy (EDS) of the cryogenic fractured surfaces of the samples were performed on a JEOL, 1200 EX model and Bruker, Quantax 70 model. The thermal stability of the composites was evaluated by thermogravimetric analysis (TGA), with a Netzsch TG 209 thermobalance operating from 20 to 860 ${ }^{\circ} \mathrm{C}$, with the following atmosphere programming: 20 to 560 
${ }^{\circ} \mathrm{C}$ with nitrogen and 560 to $860{ }^{\circ} \mathrm{C}$ with synthetic air, using

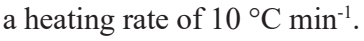

\section{Results and Discussions}

\subsection{WAXD analysis}

WAXD analysis revealed an intercalated/exfoliated morphology. In a WAXD pattern, the peak that corresponds to the clay basal spacing $\left(\mathrm{d}_{001}\right)$ is between $2^{\circ}$ and $10^{\circ}$. The complete disappearance of this peak indicates that the stacked layers of the clay were exfoliated by the polymer chains, and the shift of the peak to a lower $2 \theta$ angle indicates that the stacked layers of clay were intercalated with the EVA chains. The preservation of the diffraction peak in the nanocomposites indicates that a significant clay content remained in layered form after processing. Figure 1 shows the WAXD patterns of the BN-AM organoclay and the EVA composites.

The BN-AM organoclay showed diffraction peaks at $2 \theta$ that corresponded to d-spacing 19.6, 15.5 and $13.2 \AA$. Especially in the EVA composite containing $1.5 \mathrm{wt} \% \mathrm{BN}-\mathrm{AM}$, these peaks disappeared, indicating a favorable disordered structure of the organoclay in the polymer matrix, which may account for the tendency to produce exfoliated-clay domains. In the case of the higher organoclay content (3.0 wt\%), a single displacement peak occurred, indicating that most of the organoclay platelets were evenly stacked ${ }^{[30,31]}$. This partial destructuring of the organoclay in the matrix may be associated with the models proposed by Lagaly ${ }^{[31]}$ for the possible structural arrangements of the modifiers in the interlayer region of the clays, since $\mathrm{BN}-\mathrm{AM}$ presents a mixture of mono-, bi-layer lateral arrangements are confirmed by the absence of a single diffraction peak of up to $10^{\circ}(2 \theta)$ (Figure 1). Thus, the increase in the organoclay content has somehow hindered the process of intercalation of the polymer chains in the interlamelar region of the clay, not favoring exfoliation in the EVA matrix.

In comparison of the patterns of the BN-CT organoclay (Figure 2) revealed a diffraction peak in the composite containing $1.5 \mathrm{wt} \%$, corresponding to $18.2 \AA$. Only a slight shift of the diffraction peak occurred in this composition. This behavior does not mean that there was good intercalation of the BN-CT layer with the polymer chains, as probably

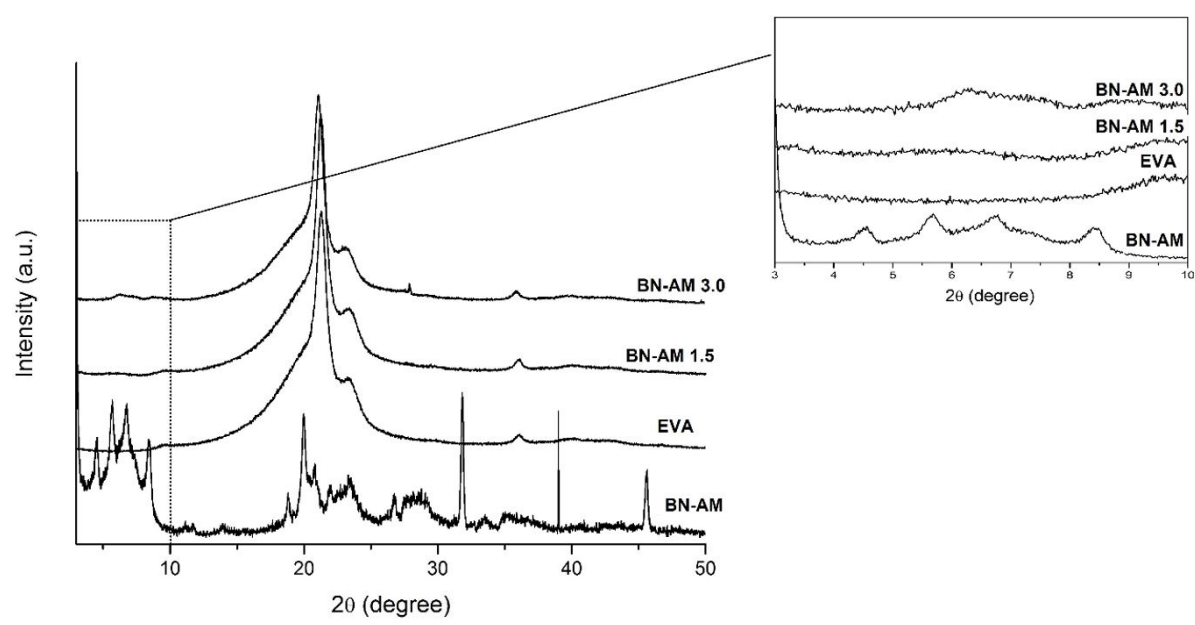

Figure 1. WAXD patterns of BN-AM organoclay, neat EVA and EVA/BN-AM composites.

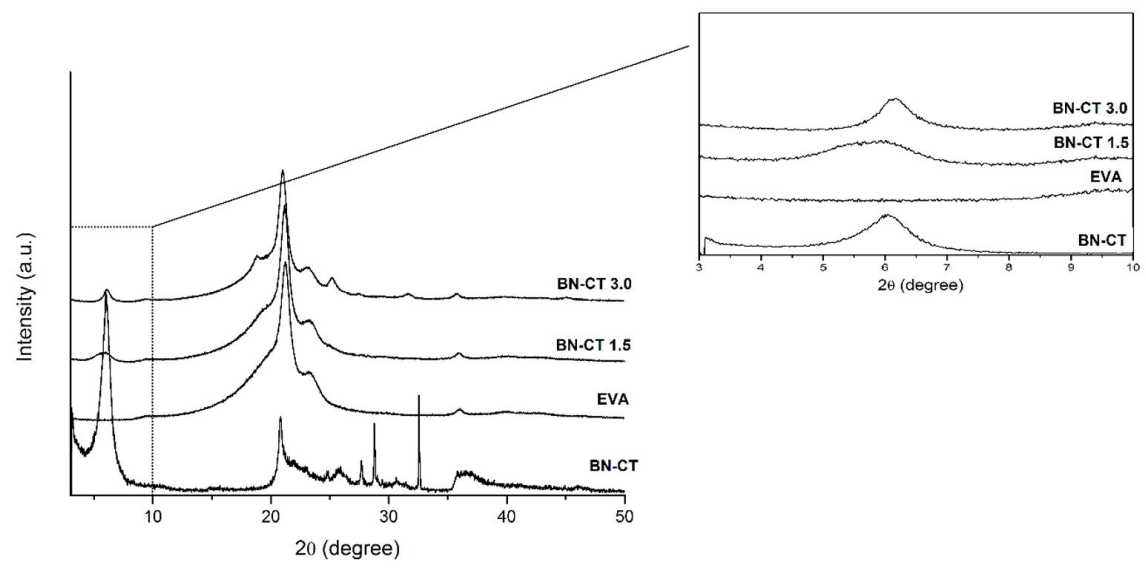

Figure 2. WAXD patterns of BN-CT organoclay, neat EVA, and EVA/BN-CT composites. 
tactoids also appeared in the structure. These structures are termed "immiscible" because the organoclay platelets exist even after melting processing. Therefore, only EVA/BN-CT microcomposites were formed ${ }^{[5]}$.

\subsection{Small amplitude oscillatory shear flow: frequency sweep and SEM/EDS morphology}

Oscillatory shear-flow analyses were performed in two configurations: (i) frequency sweep and (ii) stress relaxation. The experiments were conducted as a function of time at $180{ }^{\circ} \mathrm{C}$ and a strain of $1 \%$, defined from strain sweep test conducted to determine the linear viscoelastic region of the materials.

The variation of the complex shear viscosity $\left(\eta^{*}\right)$ as a function of the frequency of the neat EVA and the EVAorganoclay composites (EVA/BN-CT and EVA/BN-AM) is shown in Figure 3.

As seen in Figure 3, the neat EVA and all the composites showed a shear-thinning behavior, with an increase in viscosity in the low-frequency region. Figure 3 a shows that when the BN-CT organoclay was added to the EVA matrix, this matrix behaved similarly to neat EVA, however, when the BN-AM modified clay was incorporated into the EVA matrix (EVA/BN-AM 1.5), the material produced tended to show a stronger frequency-thinning comparing to neat EVA and EVA/BN-CT 1.5 composite. When $3.0 \mathrm{wt} \% \mathrm{BN}-$ AM was added to the EVA matrix (Figure $3 b$ ), the final composite tended to show an even more shear-thinning behavior when compared to EVA/BN-AM 1.5 composite.

The frequency dependency of the storage modulus $\left(G^{\prime}\right)$ of the materials obtained in the frequency $(\omega)$ sweep analysis is shown in Figure 4.

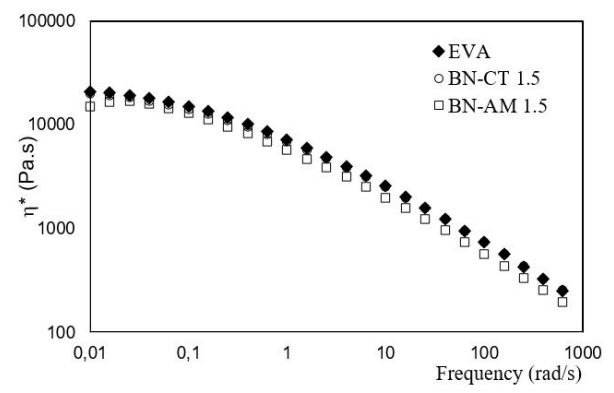

(a)

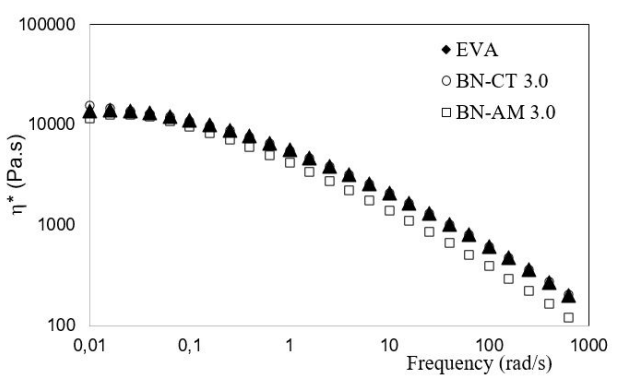

(b)

Figure 3. Frequency sweep results for neat EVA and EVA/ organoclay systems (a) $1.5 \mathrm{wt} \%$ organoclay and (b) $3.0 \mathrm{wt} \%$ organoclay.
According to Jiang et al. ${ }^{[32]}$, information on the G' value variation with frequency can indicate polymer chain structure and dynamics. Based on the present experimental data, neat EVA deviated from standard terminal behavior, showing $G^{\prime} \alpha \omega^{0.73}\left(\mathrm{R}^{2}=0.97\right)$. When $1.5 \mathrm{wt} \%$ and $3.0 \mathrm{wt} \%$ contents of BN-CT organoclay were added to EVA matrix, the relationships between $G^{\prime}$ and $\omega$ were also $G^{\prime} \alpha \omega^{0.73}\left(R^{2}=0.97\right)$, the same relationship found to neat EVA, indicating a similar rheological behavior between EVA/BN-CT systems and neat EVA. When $1.5 \mathrm{wt} \%$ and $3.0 \mathrm{wt} \%$ contents of $\mathrm{BN}-\mathrm{AM}$ organoclay were added to EVA matrix, the relationships between $G^{\prime}$ and $\omega$ were $G^{\prime} \alpha \omega^{0.68}\left(R^{2}=0.97\right)$ and $G^{\prime} \alpha \omega^{0.70}$ $\left(\mathrm{R}^{2}=0.96\right)$, respectively, indicating an improved solid-like behavior.

The variation of dynamic modulus, G' and G', was also evaluated. Table 2 presents the values of the crossover point, at which $G^{\prime}=$ G”, obtained from $G$ ' and G" versus the frequency curves. The results were evaluated by the displacement of the G' $x$ G' crossover point, which allows the flow behavior of polymeric materials to be predicted.

The data in Table 2 obtained from the results for $G^{\prime}=G^{\prime}$ ' versus frequency show that the BN-AM compositions showed the lowest modulus values at the crossover point compared with the other EVA nanocomposites. For the EVA/ BN-AM composites, a decrease in the $\mathrm{G}^{\prime}=\mathrm{G}$ ' points were observed, but with similar frequency values at the crossover point compared to the neat EVA. This may be related to the more shear-thinning behavior observed. However, these data are not in accordance with the exfoliation-like morphology observed in the EVA/BN-AM 1.5 composite, as showed in Figure 1. It was expected that a more elastic behavior at lower frequency range would be observed and, as the frequency increased, a more pronounced shear thinning had occurred.

Table 2. Dynamic modulus and frequency values at the G'/G" crossover point for neat EVA and EVA/organoclay composites.

\begin{tabular}{ccc}
\hline Sample code & $\begin{array}{c}\text { Modulus at } \\
\text { crossover point } \\
\left.\mathbf{G}^{\prime}=\mathbf{G}^{\prime} \mathbf{( 1 0}^{\mathbf{4}} \mathbf{P a}\right)\end{array}$ & $\begin{array}{c}\text { Crossover point } \\
\mathbf{\omega}_{\mathbf{c}}\left(\mathbf{r a d ~ s}^{-1}\right)\end{array}$ \\
\hline EVA & 1.81 & 10 \\
EVA/BN-CT 1.5 & 2.21 & 16 \\
EVA/BN-CT 3.0 & 1.87 & 16 \\
EVA/BN-AM 1.5 & 1.41 & 10 \\
EVA/BN-AM 3.0 & 1.35 & 10 \\
\hline
\end{tabular}

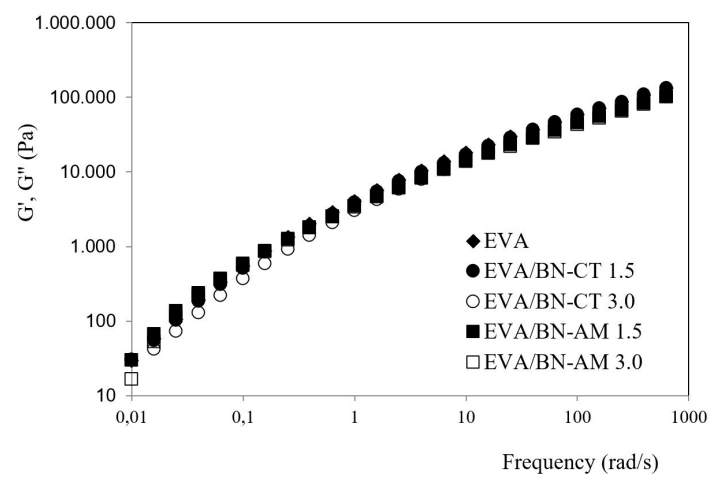

Figure 4. Storage modulus G' versus frequency curves for neat EVA and EVA/organoclay systems. 
The addition of $3.0 \mathrm{wt} \%$ of the BN-AM organoclay further decreased the $\mathrm{G}^{\prime}=\mathrm{G}$ ' values, indicating that a nanocomposite with more frequency-thinning was produced. This behavior might be related to the presence of a mixture of BN-AM arrangements in the EVA matrix, which probably favored the chain flow and it is in accordance with Figure 1. The displacement of the G' $x$ G" crossover point results also show that the addition of BN-CT organoclay in EVA matrix led to a pronounced increase in viscous behavior of the final composite. It is well known that nanofilled polymers present a viscosity increase with filler content, although in some cases a decrease of the viscosity can occur. According to La Mantia et al. ${ }^{[33]}$, the decrease of the viscosity can be explained by the occurrence of two possible mechanisms: (i) lubricant effect of the platelets when the clay particles are completely exfoliated or (ii) the occurrence of a low compatibility between polymer matrix and organoclay. It was also found from Figure 1 that the peaks disappeared in
EVA nanocomposite with $1.5 \mathrm{wt} \%$ of BN-AM, indicating the presence of exfoliated-clay domains. However, the possibility of organoclay agglomeration in the polymer matrix should also be considered. If this happened, a small clay content would occupy much less area in the polymer matrix, and so, the results observed in WAXD pattern would be leading to erroneous conclusions.

SEM/EDS analysis is a characterization tool useful to investigate the dispersion of nanofiller in a polymer matrix $^{[34,35]}$. Thus, SEM/EDS analysis was performed to evaluate the dispersion of the organoclays in the EVA matrix.

The dispersion of the organoclay (BN-AM $1.5 \mathrm{wt} \%$ composite) in EVA matrix were evaluated by SEM/EDS analysis (Figure 5).

As can be seem in Figure 5, BN-AM organoclay is well dispersed in EVA matrix, thus, the hypothesis of the occurrence of clay agglomeration, which could lead to

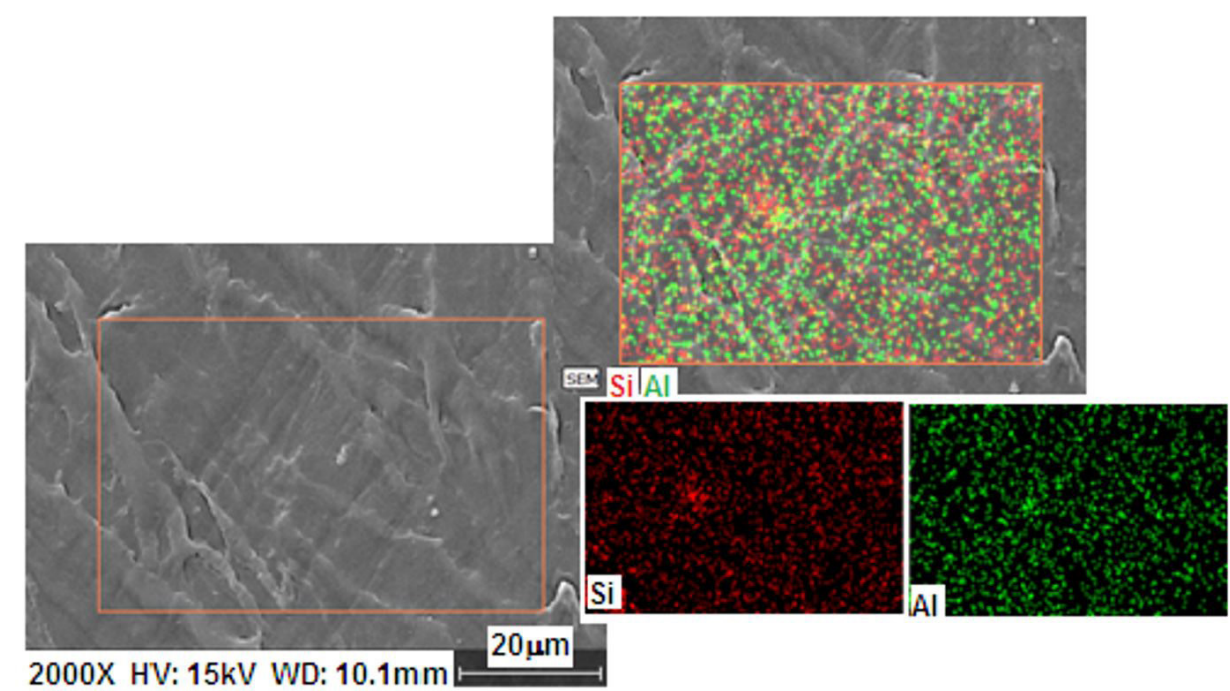

Figure 5. SEM/EDS micrographs and EDS results of BN-AM 1.5 composite.

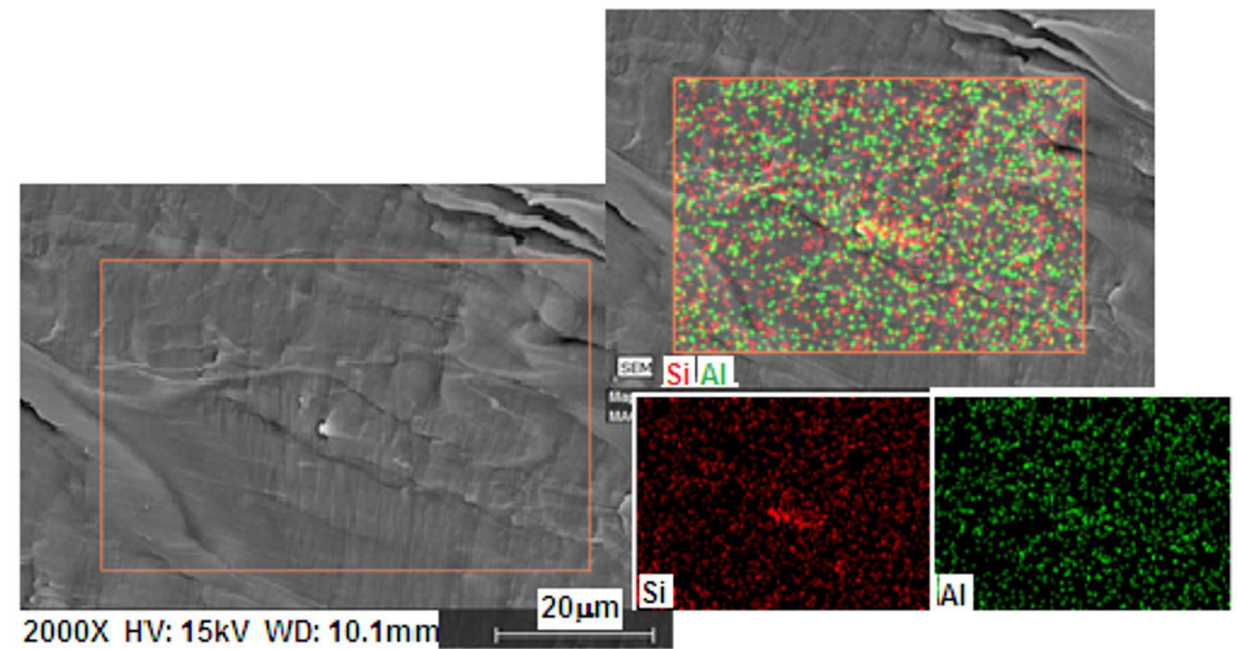

Figure 6. SEM/EDS micrographs and EDS results of BN-AM 3.0 composite. 
misinterpretations in WAXD's analysis can be discarded. Comparing SEM/EDS analysis of BN-AM 1.5 composite with that of BN-AM 3.0 composition (Figure 6), it can also be observed that even at higher BN-AM content, the dispersion of the filler in EVA matrix seems to be good. On the other hand, WAXD analysis showed a stacked morphology of the organoclay platelets on this composition (BN-AM 3.0).

The results show that the tendency of the increase of the viscous behavior can be related to the lubricant effect of the clay platelets and that this effect should occur in a more pronounced way when the organoclay platelets are evenly stacked (BN-AM 3.0 composite).

Figure 7 and 8 show SEM/EDS analysis of BN-CT 1.5 and BN-CT 3.0 composites, respectively. The micrographs show that BN-CT organoclay are also well dispersed in the matrix, although the composition with $1.5 \mathrm{wt} \%$ of $\mathrm{BN}-\mathrm{AM}$ seems to be better dispersed in the matrix when than the BN-CT 1.5 composite.

For composites based on BN-CT organoclay it seems that despite the good dispersion of BN-CT in EVA matrix, probably there is a poor interaction between nanofiller and matrix. This hypothesis corroborates the rheological results, which showed that neat EVA and BN-CT composites (BN-CT 1.5 and BN-CT 3.0) present similar flow behavior. These results are also in accordance with the WAXD analysis, which indicated that a clay fraction might remain in layered form in the BN-CT composites.

\subsection{Stress relaxation}

At a constant deformation, $\varepsilon_{0}$, and at some initial point in time, $t=0$, a slow decay of stresses over time $\sigma(t)$ can be observed. This phenomenon, called stress relaxation, can be represented by a continuous spectrum. The relaxation properties of a polymer melt are given by the relaxation modulus function, $G(t)$, which is related to the continuous spectrum $(\mathrm{H}(\lambda))$ as follows:

$$
G(t)=\int_{-\infty}^{\infty} H(\lambda)[\exp (-t / \lambda)] d(\ln \lambda)
$$

where $\lambda$ is the relaxation time ${ }^{[36,37]}$.

The stress relaxation experiments were conducted at a constant strain of $1 \%$ and at a temperature of $180^{\circ} \mathrm{C}$. Figure 9 illustrates the variation of the relaxation modulus over time of the neat EVA and the EVA/organoclay composites.

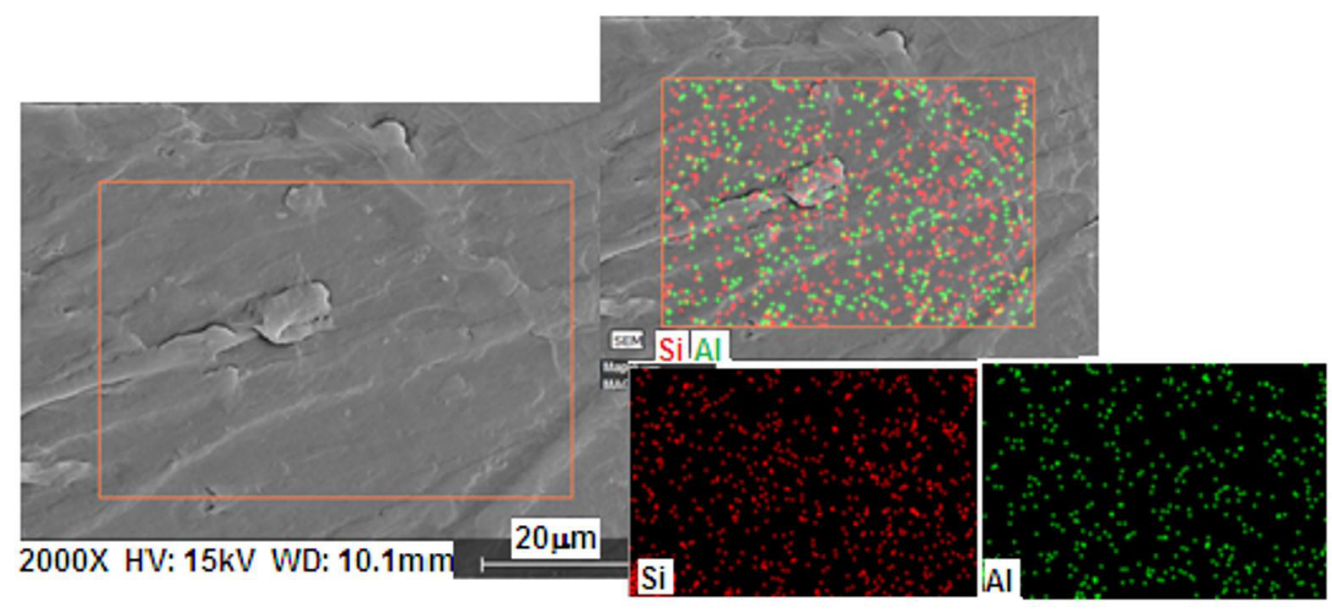

Figure 7. SEM/EDS micrographs and EDS results of BN-CT 1.5 composite.

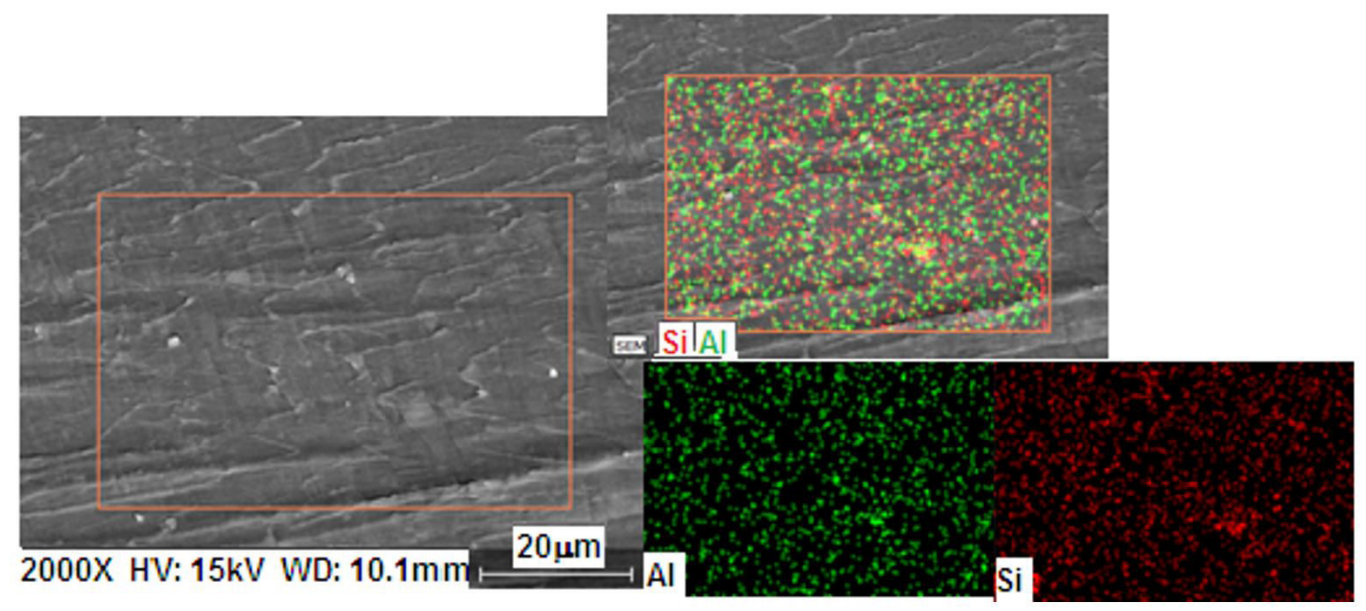

Figure 8. SEM/EDS micrographs and EDS results of BN-CT 3.0 composite. 
As seen in Figure 9, the $G(t)$ values of EVA dropped rapidly and vanished for a long period at around $500 \mathrm{~s}$ (liquid-like behavior), whereas the composites tended to extend for a long period and reached a finite pseudo-plateau (Figure 9a). A different behavior was observed for the $\mathrm{BN}-\mathrm{AM}$ composites with lower clay content (1.5 wt\%). A transition zone appeared, followed by a discreet plateau zone in which the modulus was nearly constant. At longer times, flow occurred and the $\mathrm{G}(\mathrm{t})$ curves moved into a "terminal zone", where the modulus relaxed to zero after a sufficiently long time. WAXD analysis indicated that this composition seems to have an exfoliated morphology. At short times, the network-like structure should inhibit polymer chain flow, but at longer times, this structure should disappear and flow would occur. Figure $9 \mathrm{~b}$ shows a different behavior. In the composite with $3.0 \mathrm{wt} \% \mathrm{BN}-\mathrm{AM}$, the $\mathrm{G}(\mathrm{t})$ values dropped more rapidly compared to the neat EVA and the composite with BN-CT organoclay. This may be associated with the lubricant effect showed in the EVA/BN-AM 3.0 composite, as mentioned before.

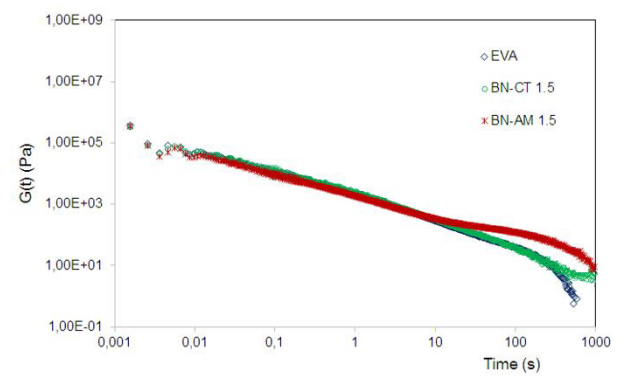

(a)

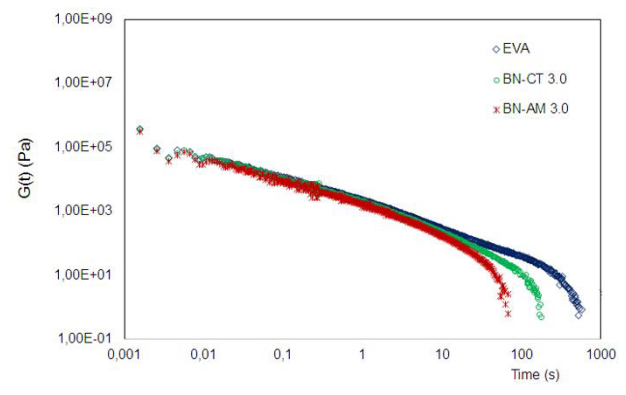

(b)

Figure 9. Variation of the relaxation modulus over time for neat EVA and EVA/organoclay systems (a) $1.5 \mathrm{wt} \%$ organoclay and (b) $3.0 \mathrm{wt} \%$ organoclay.

\subsection{Thermogravimetry analysis}

The TGA thermograms for the EVA, BN-AM and BN-CT composites show a profile well established by two subsequent mass losses (Figure 10).

In all composites, the presence of the organoclays changed the initial temperature of the first polymer-degradation step. The values of the BN-CT composites decreased compared to EVA, indicating a slight change in the thermal stability of the polymer. This degradation step is attributed to deacetylation of the EVA chain, from 200 to $400{ }^{\circ} \mathrm{C}^{[38,39]}$. Based on the literature data, modifiers based on alkyl ammonium ions degrade at a lower temperature, and this temperature is easily achieved during preparation by the melting method, causing the polymer to degrade ${ }^{[22]}$. One of the ways to explain the reported degradation of polymers by these chemical species is that the surfactant modifier present in the interlayer region of the clay is released during processing ${ }^{[40]}$.

Addition of BN-AM improved the thermal stability of the first step in EVA degradation, demonstrating that the modifier promotes slightly more stability than alkyl ammonium ion.

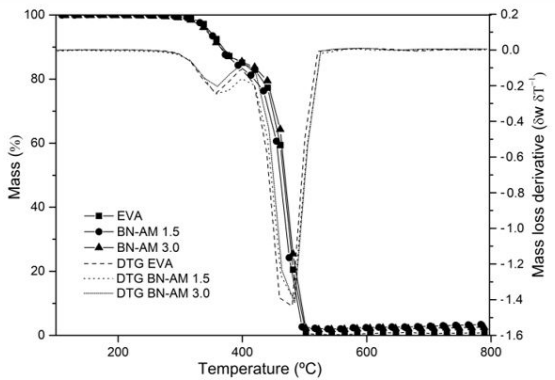

(a)

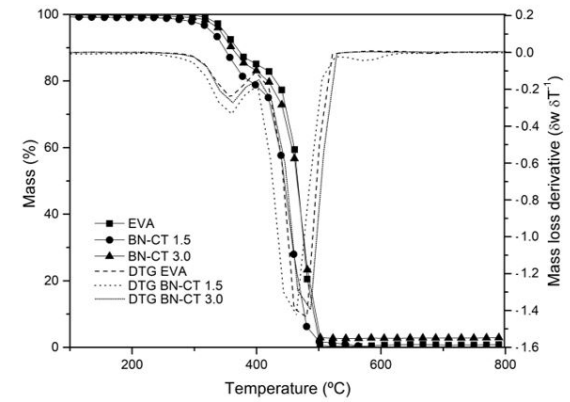

Figure 10. TGA thermograms of neat EVA, BN-AM (a) and BN-CT (b) composites. Mass loss derivative curves (DTG).

Table 3. TGA results for neat EVA and EVA/organoclay composites.

\begin{tabular}{|c|c|c|c|c|c|c|}
\hline \multirow{3}{*}{ Sample code } & \multicolumn{3}{|c|}{$1^{\text {st }}$ degradation step } & \multicolumn{3}{|c|}{$2^{\text {nd }}$ degradation step } \\
\hline & $\mathbf{T}_{\text {ONSET }}$ & $\mathbf{T}_{M A X}$ & $\mathrm{~T}_{\text {ENDSET }}$ & $\mathbf{T}_{\text {ONSET }}$ & $\mathbf{T}_{M A X}$ & $\mathbf{T}_{\text {ENDSET }}$ \\
\hline & \multicolumn{3}{|c|}{$\left({ }^{\circ} \mathrm{C}\right)$} & \multicolumn{3}{|c|}{$\left({ }^{\circ} \mathrm{C}\right)$} \\
\hline EVA & 242 & 358 & 399 & 399 & 481 & 524 \\
\hline EVA-BN-CT 1.5 & 236 & 356 & 397 & 397 & 460 & 523 \\
\hline EVA-BN-CT 3.0 & 236 & 357 & 400 & 400 & 458 & 523 \\
\hline EVA-BN-AM 1.5 & 256 & 370 & 400 & 400 & 475 & 559 \\
\hline EVA-BN-AM 3.0 & 256 & 368 & 400 & 400 & 475 & 548 \\
\hline
\end{tabular}


The $\mathrm{T}_{\text {ENDSET }}$ values of the second degradation step confirm this behavior (Table 3 ). This degradation step corresponds to cleavage of the polymer backbone and according to Beltrán et al. ${ }^{[4]}$ when the clay mineral layers are exfoliated, they reduce the volatilization of the degradation products due to the barrier properties of the organoclay, which leads to an increase in thermal stability.

TGA results of the BN-AM composites can be associated with better dispersion and interaction of the organoclay with the polymer in agreement with the WAXD patterns and rheological results.

\section{Conclusions}

We studied the effect of the modification of clay on the rheological properties of the EVA matrix, using a new nonionic modifier agent (AM). WAXD diffractograms showed that only the nanocomposites based on EVA/BN-AM, with $1.5 \mathrm{wt} \%$, did not show a diffraction peak, indicating that in this composition, stacked layers of clay were exfoliated by EVA chains when AM was used as a modifier, instead of the conventional ammonium salt modifier. However, when the EVA/BN-AM organoclay content of the EVA matrix was increased, small diffraction peaks started to appear, indicating that in this composition, a certain amount of EVA/BN-AM organoclay might have remained in layered form after processing. These results are in accordance with the observed rheological behavior. The thermogravimetry analysis showed an increase in the initial temperature of the polymer degradation process, which may be associated with an improved thermal stability of the EVA/BN-AM composite. Finally, this study allowed the evaluation of the rheological and thermal properties of EVA systems containing an alternative to the organoclay containing a new non-ionic modifier and not based on quaternary ammonium, and concluded that the addition of low BN-AM content is a promising option for the production of nanocomposites.

\section{Acknowledgements}

The authors are grateful for financial support from the National Council for Scientific and Technological Development (CNPq, 305007/2018-1), the Universidade Tecnológica Federal do Paraná (UTFPR), and IOTO International Company.

\section{References}

1. Oreski, G., Wallner, G., \& Lang, R. (2009). Ageing characterization of commercial ethylene copolymer greenhouse films by analytical and mechanical methods. Biosystems Engineering, 103(4), 489496. http://dx.doi.org/10.1016/j.biosystemseng.2009.05.003.

2. Maraveas, C. (2019). Environmental sustainability of greenhouse covering materials. Sustainability, 11(21), 6129. http://dx.doi. org/10.3390/su11216129.

3. Henderson, A. (1993). Ethylene-vinyl acetate (EVA) copolymers: a general review. IEEE Electrical Insulation Magazine, 9(1), 30-38. http://dx.doi.org/10.1109/57.249923.

4. Ismail, N. H., \& Mustapha, M. (2018). A review of thermoplastic elastomeric nanocomposites for high voltage insulation applications. Polymer Engineering and Science, 58(S1), E36-E63. http://dx.doi.org/10.1002/pen.24822.
5. Paul, D., \& Robeson, L. (2008). Polymer nanotechnology: nanocomposites. Polymer, 49(15), 3187-3204. http://dx.doi. org/10.1016/j.polymer.2008.04.017.

6. Ma, J., Duan, Z., Xue, C., \& Deng, F. (2013). Morphology and mechanical properties of EVA/OMMT nanocomposite foams. Journal of Thermoplastic Composite Materials, 26(4), 555-569. http://dx.doi.org/10.1177/0892705712458943.

7. Měřínská, D., Pata, V., Sýkorová, L., \& Šuba, O. (2019) Clay/ EVA copolymer nanocomposite: processing and properties. In B. Gapiński, M. Szostak, \& V. Ivanov (Eds.), Advances in manufacturing II (pp. 507-517). Switzerland: Springer Nature. http://dx.doi.org/10.1007/978-3-030-16943-5_43

8. Cárdenas, M. Á., Basurto, F. C., García-López, D., Merino, J. C., $\&$ Pastor, J. M. (2013). Mechanical and fire retardant properties of EVA/clay/ATH nanocomposites: effect of functionalization of organoclay nanofillers. Polymer Bulletin, 70(8), 2169-2179. http://dx.doi.org/10.1007/s00289-013-0925-0.

9. Bae, J. W., Yang, T. U., Nam, G. J., Lee, G. J., Nam, B.-U., \& Jho, J. Y. (2011). Dispersion and flame retardancy of ethylene vinyl acetate/layered silicate nanocomposites using the masterbatch approach for cable insulating material. Polymer Bulletin, 67(4), 729-740. http://dx.doi.org/10.1007/s00289011-0498-8.

10. Yue, X., Li, C., Ni, Y., Xu, Y., \& Wang, J. (2019). Flame retardant nanocomposites based on 2D layered nanomaterials: a review. Journal of Materials Science, 54(20), 13070-13105. http://dx.doi.org/10.1007/s10853-019-03841-w.

11. Urresti, O., González, A., Fernández-Berridi, M., Iruin, J., \& Irusta, L. (2011). Oxygen permeability through poly(ethyleneco-vinyl acetate)/clay nanocomposites prepared by microwave irradiation. Journal of Membrane Science, 373(1-2), 173-177. http://dx.doi.org/10.1016/j.memsci.2011.03.003.

12. Cui, Y., Kumar, S., Kona, B. R., \& Van Houcke, D. (2015). Gas barrier properties of polymer/clay nanocomposites. RSC Advances, 5(78), 63669-63690. http://dx.doi.org/10.1039/ C5RA10333A.

13. Drozdov, A. D., \& Christiansen, J. C. (2020). Micromechanical modeling of barrier properties of polymer nanocomposites. Composites Science and Technology, 189, 108002. http:// dx.doi.org/10.1016/j.compscitech.2020.108002.

14. Tjong, S. C. (2006). Structural and mechanical properties of polymer nanocomposites. Materials Science and Engineering $R$ Reports, 53(3-4), 73-197. http://dx.doi.org/10.1016/j. mser.2006.06.001.

15. Ray, S. S., \& Okamoto, M. (2003). Polymer/layered silicate nanocomposites: a review from preparation to processing. Progress in Polymer Science, 28(11), 1539-1641. http://dx.doi. org/10.1016/j.progpolymsci.2003.08.002.

16. Leite, I. F., Malta, O. L., Raposo, C. M. O., Canedo, L. E., Carvalho, L. H., \& Silva, S. M. L. (2011). Efeito de diferentes tipos de argilas e modificadores orgânicos na morfologia e propriedades térmicas dos nanocompósitos de PET. Polímeros: Ciência e Tecnologia, 21(3), 195-203. http://dx.doi.org/10.1590/ S0104-14282011005000035.

17. Zhang, W., Chen, D., Zhao, Q., \& Fang, Y. (2003). Effects of different kinds of clay and different vinyl acetate content on the morphology and properties of EVA/clay nanocomposites. Polymer, 44(26), 7953-7961. http://dx.doi.org/10.1016/j. polymer.2003.10.046.

18. Rahman, M., Zahin, F., Saadi, M. A. R., Sharif, A., \& Hoque, M. E. (2018). Surface modification of advanced and polymer nanocomposites. In N. Dasgupta, S. Ranjan, \& E. Lichtfouse (Eds.), Environmental nanotechnology. Cham: Springer. http:// dx.doi.org/10.1007/978-3-319-76090-2_6

19. Zhang, W., Chen, D., Zhao, Q., \& Fang, Y. (2003). Effects of different kinds of clay and different vinyl acetate content on 
the morphology and properties of EVA/clay nanocomposites. Polymer, 44(26), 7953-7961. http://dx.doi.org/10.1016/j. polymer.2003.10.046.

20. Ugel, E., Giuliano, G., \& Modesti, M. (2011). Poly(ethyleneco-vinyl acetate)/clay nanocomposites: effect of clay nature and compatibilising agents on morphological thermal and mechanical properties. Soft Nanoscience Letters, 01(04), 105-119. http://dx.doi.org/10.4236/snl.2011.14018.

21. Lee, K. M., \& Han, C. D. (2003). Rheology of organoclay nanocomposites: effects of polymer matrix/organoclay compatibility and the gallery distance of organoclay. Macromolecules, 36(19), 7165-7178. http://dx.doi.org/10.1021/ma030302w.

22. Cui, L., Khramov, D. M., Bielawski, C. W., Hunter, D. L., Yoon, P. J., \& Paul, D. R. (2008). Effect of organoclay purity and degradation on nanocomposite performance, Part 1: surfactant degradation. Polymer, 49(17), 3751-3761. http:// dx.doi.org/10.1016/j.polymer.2008.06.029.

23. Wang, G., Wang, S., Sun, Z., Zheng, S., \& Xi, Y. (2017). Structures of nonionic surfactant modified montmorillonites and their enhanced adsorption capacities towards a cationic organic dye. Applied Clay Science, 148, 1-10. http://dx.doi. org/10.1016/j.clay.2017.08.001.

24. Zhuang, G., Zhang, Z., \& Jaber, M. (2019). Organoclays used as colloidal and rheological additives in oil-based drilling fluids: an overview. Applied Clay Science, 177, 63-81. http:// dx.doi.org/10.1016/j.clay.2019.05.006.

25. Morita, R. Y., Kloss, J. R., \& Barbosa, R. V. (2014). Characterization of mechanical and thermal properties of poly(ethylene-co-vinyl acetate) with differents bentonites. Macromolecular Symposia, 343(1), 88-95. http://dx.doi.org/10.1002/masy.201300198.

26. Carli, L. N., Daitx, T. S., Guégan, R., Giovanela, M., Crespo, J. S., \& Mauler, R. S. (2014). Biopolymer nanocomposites based on poly(hydroxybutyrate-co-hydroxyvalerate) reinforced by a non-ionic organoclay. Polymer International, 64(2), 235-241. http://dx.doi.org/10.1002/pi.4781.

27. Morita, R. Y., Kloss, J. R., \& Barbosa, R. V. (2015). Caracterização de bentonitas sódicas: efeito o tratamento com surfactante orgânico livre de sal de amônio. Revista Virtual de Química, 7(4), 1286-1298. http://dx.doi.org/10.5935/1984-6835.20150071.

28. Iodice, B., Torrens, G. L., Kloss, J. R., Reis, D. M., \& Jarek, F. (2010) $B R \mathrm{n}^{\circ}$ PI 10013121. Processo de obtenção de nanoargila modificada para a produção de nanocompósitos poliméricos e nanoargila modificada.

29. Iodice, B., Morita, R. Y., Kloss, J. R., Torrens, G. L., \& Barbosa, R. V. (2013) WO 2013/185196 A1. Use of an ammonium salt-free organophilic nanostructured clay in polyethylene.

30. Pistor, V., Lizot, A., Fiorio, R., \& Zattera, A. J. (2010). Influence of physical interaction between organoclay and poly(ethylene-co-vinyl acetate) matrix and effect of clay content on rheological melt state. Polymer, 51(22), 5165-5171. http:// dx.doi.org/10.1016/j.polymer.2010.08.045.

31. Lagaly, G. (1986). Interaction of alkylamines with different types of layered compounds. Solid State Ionics, 22(1), 43-51. http://dx.doi.org/10.1016/0167-2738(86)90057-3.

32. Jiang, L., Zhang, J., \& Wolcott, M. P. (2007). Comparison of polylactide/nano-sized calcium carbonate and polylactide/ montmorillonite composites: reinforcing effects and toughening mechanisms. Polymer, 48(26), 7632-7644. http://dx.doi. org/10.1016/j.polymer.2007.11.001.

33. La Mantia, F. P., Scaffaro, R., Ceraulo, M., Mistretta, M. C., Dintcheva, N. T. Z., \& Botta, L. (2016). A simple method to interpret the rheological behavior of intercalated polymer nanocomposites. Composites. Part B, Engineering, 98, 382388. http://dx.doi.org/10.1016/j.compositesb.2016.05.045.

34. Lotti, C., Isaac, C. S., Branciforti, M. C., Alves, R. M. V., Liberman, S., \& Bretas, R. E. S. (2008). Rheological, mechanical and transport properties of blown films of high density polyethylene nanocomposites. European Polymer Journal, 44(5), 1346-1357. http://dx.doi.org/10.1016/j. eurpolymj.2008.02.014.

35. Son, D., Cho, S., Nam, J., Lee, H., \& Kim, M. (2020). X-raybased spectroscopic techniques for characterization of polymer nanocomposite materials at a molecular level. Polymers, 12(5), 1053. http://dx.doi.org/10.3390/polym12051053. PMid:32375363.

36. Malkin, A. Y. (1994). Rheology fundamentals. Toronto: ChemTec Publishing.

37. Oliveira, A. G., Moreno, J. F., de Sousa, A. M. F., Escócio, V. A., Guimarães, M. J. O. C., \& da Silva, A. L. N. (2020). Composites based on high-density polyethylene, polylactide and calcium carbonate: effect of calcium carbonate nanoparticles as co-compatibilizers. Polymer Bulletin, 77(6), 2889-2904. http://dx.doi.org/10.1007/s00289-019-02887-9.

38. Allen, N. S., Edge, M., Rodriguez, M., Liauw, C. M., \& Fontan, E. (2000). Aspects of the thermal oxidation of ethylene vinyl acetate copolymer. Polymer Degradation \& Stability, 68(3), 363-371. http://dx.doi.org/10.1016/S0141-3910(00)00020-3.

39. Rimez, B., Rahier, H., Van Assche, G., Artoos, T., Biesemans, M., \& Van Mele, B. (2008). The thermal degradation of poly(vinyl acetate) and poly(ethylene-co-vinyl acetate), Part I: experimental study of the degradation mechanism. Polymer Degradation \& Stability, 93(4), 800-810. http://dx.doi. org/10.1016/j.polymdegradstab.2008.01.010.

40. He, H., Ding, Z., Zhu, J., Yuan, P., Xi, Y., Yang, D., \& Frost, R. L. (2005). Thermal characterization of surfactant-modified montmorillonites. Clays and Clay Minerals, 53(3), 287-293. http://dx.doi.org/10.1346/CCMN.2005.0530308.

41. Beltrán, M. I., Benavente, V., Marchante, V., Dema, H., \& Marcilla, A. (2014). Characterization of montmorillonites simultaneously modified with an organic dye and an ammonium salt at different dye/salt ratios: properties of these modified montmorillonites EVA nanocomposites. Applied Clay Science, 97-98, 43-52. http://dx.doi.org/10.1016/j.clay.2014.06.001.

Received: Mar. 23, 2020

Revised: Aug. 10, 2020

Accepted: Aug. 20, 2020 